\title{
Antisocial Behavior is Associated with Reduced Frontoparietal Activity to Loss in a Population-Based
}

\section{Sample of Adolescents}

\author{
Laura Murray \\ McLean Hospital, Belmont, MA, USA \& Department of Psychiatry, Harvard Medical School, Boston, MA, \\ USA
}

Nestor L. Lopez-Duran

Department of Psychology, University of Michigan, Ann Arbor, MI, USA

\section{Colter Mitchell}

Survey Research Center of the Institute for Social Research \& Population Studies Center of the Institute for Social Research, University of Michigan, Ann Arbor, MI, USA

\section{Christopher S. Monk}

Department of Psychology, Survey Research Center of the Institute for Social Research \& Department of Psychiatry, University of Michigan, Ann Arbor, MI, USA

Luke W. Hyde*

Department of Psychology \& Institute for Social Research, University of Michigan, Ann Arbor, MI, USA

Draft version 1, 6/2/21. This manuscript is currently under peer review. Please do not copy or cite without author's permission

\footnotetext{
* Corresponding author: Luke W. Hyde; Department of Psychology, University of Michigan; 2229 East Hall, 530 Church St., Ann Arbor, MI 48109; Phone: (734) 763-4132; lukehyde@umich.edu
} 


\begin{abstract}
Background: Adolescent antisocial behavior $(A B)$ is a public health concern due to the high financial and social costs of $A B$ on victims and perpetrators. Neural systems involved in reward and loss processing are thought to contribute to $A B$. However, investigations into these processes are limited: few have considered anticipatory and consummatory components of reward, response to loss, nor whether associations with $A B$ may vary by level of callous-unemotional (CU) traits.
\end{abstract}

Methods: A population-based, community sample of 128 predominantly low-income youth (mean age $=15.9$ years; $42 \%$ male) completed a monetary incentive delay task during fMRI. A multi-informant, multi-method latent variable approach was used to test associations between $A B$ and neural response to reward and loss anticipation and outcome, and whether these associations were moderated by $\mathrm{CU}$ traits.

Results: $A B$ was not associated with neural response to reward but was associated with reduced frontoparietal activity during loss outcomes. This association was moderated by CU traits such that individuals with higher levels of $A B$ and $C U$ traits had the largest reductions in frontoparietal activity. Cooccurring $A B$ and $C U$ traits were also associated with increased precuneus response during loss anticipation.

Conclusions: Findings indicate that $A B$ is associated with reduced activity in brain regions involved in cognitive control, attention, and behavior modification during negative outcomes. Moreover, these reductions are most pronounced in youth with co-occurring $\mathrm{CU}$ traits. These findings have implications for understanding why adolescents involved in $A B$ continue these behaviors despite severe negative consequences (e.g., incarceration). 


\section{Introduction}

Antisocial behavior $(A B)$ refers to acts of aggression, rule-breaking, and delinquency, and is the foundation of the diagnosis of Conduct Disorder (CD) in the Diagnostic and Statistical Manual of Mental Disorders (DSM-5; American Psychiatric Association, 2013). Adolescent AB is a major public health concern due to the chronic trajectory of $A B$, leading to substantial long-term costs for perpetrators, victims of $A B$, and to society broadly (Foster \& Jones, 2005). Despite theory and behavioral research emphasizing the role of dysfunctional reward and punishment-related decision making in $A B$ (Blair, 2015a; Fowles, 1980; Hoppenbrouwers, Neumann, Lewis, \& Johansson, 2015), there is relatively little research investigating the associations between $A B$ and neural response to reward and punishment (Byrd, Loeber, \& Pardini, 2014; Murray, Waller, \& Hyde, 2018).

\section{Reward Processing in Antisocial Behavior}

Behavioral and neurobiological studies indicate that youth engaging in high levels of $A B$ persist with previously rewarded behaviors, even when reward contingencies change (Blair, 2015a, 2015b; Byrd et al., 2014). Several studies have examined the neural mechanisms that underlie disrupted reward processing in youth AB (Bjork, Chen, Smith, \& Hommer, 2010; Cohn et al., 2015; Crowley et al., 2010; Finger et al., 2011; Gatzke-Kopp et al., 2009; Murray, Shaw, Forbes, \& Hyde, 2017; Veroude et al., 2016; White et al., 2013). These studies have primarily focused on the ventral striatum (VS), a hub of the reward circuit that is key for reward motivation, valuation, and response (Haber \& Knutson, 2010; Heekeren et al., 2007). Yet, the direction of the associations between youth $A B$ and reward-related neural processing are mixed (for reviews see, Byrd et al., 2014; Murray et al., 2018). For example, prior work has shown that adolescents with "externalizing" behaviors have increased VS activation during reward outcomes (Bjork et al., 2010) and when expected rewards are not received (Gatzke-Kopp et al., 2009), while other studies have linked adolescent $A B$ to reduced VS reactivity during risky-decision making (Crowley et al., 2010), and passive avoidance learning (Finger et al., 2011). 
There are several possible explanations for the seemingly conflicting findings regarding the relationship between $A B$ and reward processing. First, $A B$ is a heterogeneous construct with subgroups that have potentially different etiologies. Callous-Unemotional (CU) traits - which includes low empathy, remorse, and interpersonal affect - delineate a group of youth high on $A B$, with a more stable and severe pattern of $A B$, and different behavioral, genetic, and neural correlates (Frick, Cornell, Barry, Bodin, \& Dane, 2003a). Thus, the DSM-5 added CU traits as a specifier of the CD diagnosis ("with limited prosocial emotions") to delineate youth that may have a different trajectory and etiology to their $A B$ (American Psychiatric Association, 2013). Discrepancies in findings of reward-related neural functioning may be attributed to the (often unmeasured) presence (or absence) CU traits in each sample. To date, few studies have investigated how $C U$ traits might influence associations between $A B$ and reward processing in youth (Cohn et al., 2015; Murray et al., 2017).

A second factor potentially contributing to conflicting findings is the considerable methodological heterogeneity across neuroimaging investigations of reinforcement processing. Reward and loss processing include distinct phases (e.g., anticipation, consumption, learning), which have unique patterns of neural activation across a network of corticolimbic brain regions (Berridge \& Robinson, 2003; Knutson \& Greer, 2008). AB and impulsive-antisocial psychopathic traits have been linked to increased neural reactivity in frontostriatal regions during reward anticipation, but not outcome (Buckholtz et al., 2010; Murray et al., 2018), highlighting the importance of examining potential neural dysfunction within specific phases of reward processing.

Beyond explaining discrepancies in the existing (small) literature, two other limitations of the literature need to be addressed. First, despite behavioral research that indicates abnormal punishment processing as playing a key role in AB (Matthys, Van Goozen, Snoek, \& Van Engeland, 2004; Newman, Widom, \& Nathan, 1985), few studies have examined associations between AB and neural responses to negative outcomes such as monetary loss (Byrd, Hawes, Burke, Loeber, \& Pardini, 2018; Gregory et al., 
2015). Second, most neuroimaging research on $A B$ is conducted using either relatively small groups of youth with severe $A B$ or samples of very healthy participants who reside near major research universities. Both of these sampling strategies have their respective strengths and limitations, either by examining neural response to reward in extreme groups, thus not capturing the dimensional nature of AB (Krueger, Markon, Patrick, Benning, \& Kramer, 2007), or by recruiting non-representative, advantaged and very healthy community samples, which may limit the reliability and generalizability to the general population (e.g., across a range of racial/ethnic groups and socioeconomic status) (Button et al., 2013; Chiao, 2009; Chiao \& Cheon, 2010). Recruiting participants from under-represented and underserved groups (e.g., African Americans) is particularly important for research on $A B$ due to these groups' disproportionate exposure to systemic racism, which leads to greater exposure to low-income, dangerous neighborhoods, which place youth at greater risk for AB (Leventhal \& Brooks-Gunn, 2000). Moreover, youth of color are more likely to experience harsher consequences for risky-behavior than non-minority youth (e.g., incarceration) (Burch, 2015). Questions of generalizability and replicability of neuroimaging findings to broader, more representative samples highlight the critical importance of examining brain-behavior relationships in well-sampled cohorts that include substantial representation of participants of color (Falk et al., 2013; Hyde, Tompson, Creswell, \& Falk, 2015).

\section{Current Study}

The current study contributes to a small but growing body of work on neural reward and loss processing in youth $A B$. The study seeks to fill gaps in the previous literature by investigating associations between $A B$ and neural activity during both anticipatory and consummatory phases of reward and loss processing in a sample of primarily low SES adolescents, the majority of which identify as youth of color. In addition to examining associations to neural response to both reward and loss, the study examines whether $\mathrm{CU}$ traits moderate any associations between $\mathrm{AB}$ and neural activity during 
adolescence, a critical developmental period when AB becomes more common and severe (Shaw, Hyde, \& Brennan, 2012).

\section{Method}

\section{Participants}

Participants were 237 youth from the Study of Adolescent Neural Development (SAND) who participated in the longitudinal Fragile Families and Child Wellbeing Study (FFCWS; Reichman, Teitler, Garfinkel, \& McLanahan, 2001). The FFCWS is a longitudinal population-based sample of infants born in hospitals in twenty US cities (population >200,000) between 1998 and 2000. The study was oversampled 3:1 for non-marital births. Based on this sampling frame (urban, non-marital births), the resulting sample was enriched for families with lower-income and substantial representation of families of color. At the time of recruitment, $42 \%$ of the sample reported an annual household income of $<\$ 25,000$. Families in the FFCWS completed interview-based assessments when target youth were 1, 3, 5, 9, 15 years old. The current sample consists of youth born in three of the original 20 cities: Detroit, MI, Toledo, OH, and Chicago, IL. 195 youth completed the fMRI scanning session. Of the 128 youth with usable fMRI data in the present analyses (Supplemental Table 1), the average age was 15.9 years old (range 15.0-17.6); 58\% were female; 76\% were Black/African American, $12 \%$ were White/European American; and $40.6 \%$ had an annual family income of below $\$ 25,000$ (Supplemental Table 2; Murray, Lopez-Duran, Mitchell, Monk, \& Hyde, 2020). Youth also completed self-report questionnaires and a psychiatric interview. Primary caregivers completed self-report questionnaires, questionnaires about their child, and psychiatric interviews about their and their child's mental health. The University of Michigan institutional review board approved all procedures.

\section{Measures}

Monetary incentive Delay task. Participants completed a point-based, modified version of the Monetary Incentive Delay (MID) task during fMRI (Supplemental Figure 1; Murray et al., 2020). The task 
consisted of 90 trials, presented in two, 45-trial, 9.4-minute runs. In each trial, participants saw a cue indicating the trial type (potential win, loss, or no-change/neutral), then a variable fixation crosshair delay, then a target (white square), followed by a jittered inter-trial interval. Participants were instructed to respond to the target with their right index finger to win or avoid losing points. Task difficulty was adjusted using a performance tracking algorithm so that each participant successfully responded to $\sim 50 \%$ of the trials. Participants completed a practice session outside of the scanner to ensure task understanding and to determine the initial response window. The task used in the current study produced a robust response in the extended corticolimbic circuit and was also able to separate the anticipation and consumption phases of reward and loss via additional jitter (2-4 sec) between trials (Murray et al., 2020).

Antisocial Behavior. AB was assessed using a multi-informant, multi-method approach which combined several indicators of $A B$ using self-report, parent-report, and clinical diagnostic assessment as done previously in this sample (Dotterer et al., 2020). AB was assessed using the (a) total score from the youth-reported Self-Report of Delinquency (Elliott, Huizinga, \& Ageton, 1985), (b) rule-breaking, and (c) aggression subscales from the parent-reported Child Behavior Checklist (CBCL; Achenbach, 1991; Achenbach, Dumenci, \& Rescorla, 2003), and (d) combined lifetime CD and oppositional defiant disorder (ODD) symptom counts from the clinician-rated Schedule for Affective Disorders and Schizophrenia for School-Age Children-Present and Lifetime diagnostic interview (K-SADS; Kaufman et al., 1997). The four measures were modestly-to-strongly correlated (range, $r=.30-.81$, all $p s<.001$; Supplemental Table 3). To create a multi-method, multi-informant, dimensional measure of $A B$, we used confirmatory factor analysis (CFA) in Mplus (Version 7.3; Muthén \& Muthén, 2014) with maximum likelihood estimation with robust standard errors. Scale loadings on the latent $A B$ factor were moderate-to-high ( $\beta=.39-.93, p$ $<.001$; Supplemental Table 3). 
Assessment of Callous-Unemotional Traits. Similar to the assessment of AB, we used several indicators to create a multi-informant, multi-method dimensional measure of CU traits (Dotterer et al., 2020). CU traits were assessed using total scores from the (a) parent-reported and (b) youth-reported Inventory of Callous-Unemotional Traits (Frick, 2004), and (c) clinician-rated total lifetime symptom counts from the Michigan Addendum to the K-SADS (Walker et al., 2020), which consisted of items derived from the Clinical Assessment of Prosocial Emotions (CAPE; Frick, 2016) to assess the Limited Prosocial Emotions specifier of CD in the DSM-5. The three measures were modestly correlated $(r=.13-$ .35, all ps <.05; Supplemental Table 4). A latent factor was created in MPlus (Muthén \& Muthén, 2014) using CFA with full information maximum likelihood estimation with robust standard errors. Scale loadings were moderate-to-high ( $\beta=.35-.86, p<.001$; Supplemental Table 4).

Other Variables included as Covariates. To account for potential demographic or developmental effects, we included the following covariates in all fMRI analyses: (a) self-reported race, a social construct used here to address differences in exposures to personal and systemic racism and other unequal exposures (two dichotomous codes: Black/African American vs. Other; White/European American vs. Other) (Phinney, 2010); (b) parent-reported annual family income; (c) youth age (months); (d) self-reported gender; and (e) self-reported pubertal development, using the Pubertal Development Scale (Murray et al., 2020; Petersen, Crockett, Richards, \& Boxer, 1988).

\section{Analysis}

BOLD fMRI acquisition and pre-processing. Youth were scanned with a GE Discovery MR750 3T MRI scanner with an 8-channel head coil. T1-weighted gradient echo images were taken before the functional scans $\left(\mathrm{TR} / \mathrm{TE}=9.0 / 1.8 \mathrm{~ms}, \mathrm{TI}=500 \mathrm{~ms}\right.$, flip angle $=15^{\circ}, \mathrm{FOV}=26 \mathrm{~cm}$; slice thickness $=1.4 \mathrm{~mm}$; $256 \times 256$ matrix; 40 slices). Functional T2*-weighted BOLD images were acquired using a reverse spiral sequence with interleaved contiguous axial $3 \mathrm{~mm}$ slices (TR/TE $=2000 / 30 \mathrm{~ms}$, flip angle $=90, \mathrm{FOV}=22$ $\mathrm{cm}$ ) aligned with the AC-PC plane. Functional images were positioned to maximize limbic coverage. An 
auto-shimming procedure was conducted to reduce field inhomogeneity. The standard pre-processing procedure from the University of Michigan fMRI Center was applied, including removing outliers from the raw k-space data, image reconstruction, fieldmap correction, and slice-timing correction. Using SPM12 (http://www.fil.ion.ucl.ac.uk/spm/), high-resolution anatomical images were re-oriented to the AC-PC plane, gray matter segmented, and functional images were realigned, co-registered, normalized, and smoothed with an 8mm FWHM Gaussian filter.

Artifact detection Tools (ART) software (http://www.nitrc.org/projects/artifact_detect/) was used to identify motion outliers ( $>2 \mathrm{~mm}$ movement or $3.5^{\circ}$ rotation) that were removed in the statistical model via spike regression. Due to our focus on the VS, participants were only included in subsequent analyses if there was a minimum of $70 \%$ coverage in the VS using an anatomically defined bilateral region of interest (ROI). Two spheres of $10 \mathrm{~mm}$ radius were created in WFU PickAtlas Tool v3.0.5 around the Montreal Neurological Institute (MNI) coordinates $x= \pm 12, y=12$, and $z=-10$ to encompass the bilateral VS (Murray et al., 2017). Data were also visually inspected for signal drop out and poor whole brain coverage (particularly in reward-related regions including the prefrontal cortex and limbic system). As described previously in this task and sample (Murray et al., 2020), additional data quality assessments were done to assess for outliers. Six subjects were excluded due to having several large, or many small movement artifacts, despite having fewer than $20 \%$ outlier scans identified with ART. Analyses including these subjects are similar to those reported in the main text (Supplemental Table 5). Participant exclusions due to MRI contraindications, behavioral data, and MRI processing are presented in Supplemental Table 1.

In addition to testing associations between $A B$ and reward- and loss-related neural response at the whole-brain level, we also examined associations within the VS, a key node of the reward circuit, using a small-volume correction. 3dClustSim (Cox, Chen, Glen, Reynolds, \& Taylor, 2017) was used for multiple comparison correction using a Monte Carlo simulation to achieve a correction of $p<.05$. Spatial 
autocorrelation (ACF) values for a random $10 \%$ of the sample were calculated from the first level model residuals using $3 \mathrm{dFWHMx}$ in AFNI. ACF values (mean values: $0.512,6.737,12.656$ ) were used in 3dClustSim to estimate the noise smoothness using a Gaussian plus mono-exponential function. We used a voxel-wise correction of $p<.001$. Resulting cluster thresholds were $k=5$ for the VS ROI and $k=131$ for whole-brain analyses.

Neural response to reward and loss in $A B$. To test for associations between $A B$ and neural response to reward and loss, multiple regression analyses were conducted using SPM12. Separate multiple regression analyses of $A B$ and $C U$ traits as predictors were examined in contrasts allowing for the separation of anticipation and consumption phases: 1) Reward Anticipation > Reward Win 2) Loss Anticipation > Loss Outcome. Neural responses for expected versus unexpected outcomes within the context of reward and loss trials were also examined: 3) Reward Win > No-Win Trials, and 4) Loss Outcome $>$ No Loss. We also examine the potential moderating effect of $\mathrm{CU}$ traits on associations between $A B$ and neural response. We hypothesized that $A B$ would be associated with increased VS response during reward anticipation and that $\mathrm{CU}$ traits would not be associated with reward function (Murray et al., 2018). Given the limited research on neural response to loss, we hypothesized that $A B$ would be associated with neural response to loss and that CU traits would moderate this association; however, we did not make specific directional hypotheses.

We present the results of models that include the primary predictor (i.e., AB or CU traits) and demographic covariates (i.e., age, gender, pubertal status, annual family income, and self-reported race), and for the moderation analyses, the $A B \times C U$ interaction term, the main effects of $A B$ and $C U$ traits, and demographic covariates. Analyses of the zero-order associations (e.g., AB without covariates) and analyses accounting for shared variance of $A B$ and $C U$ traits (e.g., $A B$ controlling for $C U$ traits) were similar to those reported in the main text (Supplemental Table 6).

\section{Results}




\section{Is $\mathrm{AB}$ related to Neural Response to Reward?}

$A B$ was not associated with neural reactivity to Reward Anticipation > Reward Outcome, nor Reward Win > No Win contrasts.

\section{Is $A B$ related to Neural Response to Loss?}

$A B$ was negatively correlated with several large clusters (i.e., reduced reactivity) during Loss Outcome $>$ No Loss (Table 1, Figure 1). This included the inferior frontal gyrus $(t=-6.34, k=2732, x$ $=-48, y=16, z=20)$, inferior and superior parietal lobules $(t=-6.17, k=10030, x=22, y=-62, z=52)$, inferior and middle temporal gyrus $(t=-4.70, k=158, x=58, y=-46, z=-12)$, fusiform and lingual gyri ( $t$ $=-4.45, k=697, x=-42, y=-62, z=-14)$, occipital gyrus $(t=-4.32, k=176, x=-18, y=-94, z=8)$, and caudate $(t=-4.30, k=332, x=18, y=10, z=20)$. AB was not associated with neural reactivity to Loss Anticipation > Loss Outcome, nor was AB associated with loss-related reactivity in the VS ROI.

\section{Are CU traits related to Neural Response to Reward?}

CU traits were not associated with neural reactivity to Reward Anticipation > Reward Outcome, nor Reward Win > No Win contrasts.

\section{Are CU traits related to Neural Response to Loss?}

$\mathrm{CU}$ traits were associated with reduced neural response to Loss Outcome $>$ No Loss in the middle frontal gyrus $(t=-4.23, k=436, x=-44, y=18, z=40)$ and the superior parietal lobule $(t=-3.95$, $k=186, x=-22, y=-54, z=50$ ) (Table 1, Figure 2). These regions overlapped with those identified in the $A B$ analyses, and did not survive when controlling for $A B$ (Supplemental Table 6). $C U$ traits were not associated with Loss Anticipation > Loss Outcome, nor loss-related reactivity in the VS ROI.

\section{Do CU traits Moderate on Neural Response to Reward and Loss in AB?}

There was a significant interaction between $A B$ and $C U$ Traits for both loss-related analyses. Specifically, the interaction of $A B$ and $C U$ traits predicted increased activity in the right precuneus and angular gyrus during Loss Anticipation $>$ Loss Outcome $(t=4.54, k=441, x=30, y=-64, z=40)$, and this 
effect was driven by a reduced response in those with low CU traits, and an increased response in those with high CU traits (Table 1, Figure 3).

The interaction of $A B$ and $C U$ traits predicted reduced frontoparietal reactivity to Loss Outcome $>$ No Loss such that the pattern of reduced activation was strongest for those with high levels of CU traits (Table 1, Figure 1C). Clusters largely overlaped with the results of the $A B$ analyses. The largest frontoparietal cluster included the inferior frontal gyrus, superior parietal lobule, cingulate, and precuneus $(t=-6.74, k=14315, x=-52, y=8, z=28)$ and additional clusters included the middle and inferior temporal gyri $(t=-5.67, k=192, x=56, y=-62, z=-2)$, and mid-cingulate $(t=-3.93, k=241, x=-$ $14, y=14, z=38)$.

\section{Discussion}

The current study investigated associations between $A B, C U$ traits, and neural processing of reward and loss in a population-based sample of youth born in medium-sized US cities. We improved upon previous research by (a) using a task designed to measure neural responses to the anticipation and consumption, (b) including the examination of reward and loss, and (c) examining whether co-occurring levels of CU traits impacted findings using a multi-method multi-informant latent variable approach. Contrary to our hypothesis, $A B$ and $C U$ traits were not associated with neural response to reward. In line with our hypotheses, $A B$ and $C U$ traits were associated with neural processing of loss. Specifically, $A B$ was associated with decreased reactivity across a widespread frontoparietal network during loss outcomes. These links were moderated by CU traits such that the pattern of reduced reactivity was strongest for youth with higher levels of $C U$ traits. Finally, although $A B$ and $C U$ traits were not independently linked to neural response during loss anticipation, the interaction of $A B$ and $C U$ traits was associated with greater angular gyrus and precuneus activity during loss anticipation. Our findings of reduced neural response to loss in $A B$ and $C U$ traits provide support for loss-processing as an important target for continued research to inform our understanding of $A B$. Moreover, these findings underscore 
the importance of investigating the unique and moderating effects of $\mathrm{CU}$ traits in youth who engage in $A B$ and the decomposition of anticipation versus consumption of reward and loss.

$A B$ was associated with a large cluster of reduced frontoparietal activation during loss outcomes. The regions of reduced neural activation, including the inferior parietal lobes and inferior and middle frontal gyri, correspond with key nodes of the frontoparietal control network (Dixon et al., 2018; Seeley et al., 2007). This network is engaged during tasks requiring working memory and behavioral and cognitive control (Seeley et al., 2007), and components of this network have distinct connections with the default mode network and dorsal attention network (Dixon et al., 2018). Prior work suggests that activation in these regions contributes to mapping stimulus-response associations and their relationship to reward outcomes (Dixon \& Christoff, 2012). Also, prior work has found that youth AB is associated with reduced resting-state functional connectivity (Lin, Tseng, Lai, Matsuo, \& Gau, 2015) and reduced task-based activation during loss processing (Schwenck et al., 2017) within the frontoparietal network. Thus, our findings may suggest that youth high on $A B$ fail to recruit cognitive and attentional neural circuitry necessary for behavior modulation in response to negative outcomes. These results are also consistent with behavioral studies of youth $A B$ (Byrd et al., 2014), showing impairments in passive avoidance learning (e.g., Newman \& Kosson, 1986) and response reversal (e.g., Budhani \& Blair, 2005), both of which require related cognitive and attentional resources.

The association between $A B$ and reduced frontoparietal response to loss was most pronounced in youth with higher levels of CU traits. Reduced reactivity to loss outcomes may suggest that youth high on $A B$ and $C U$ traits may be less sensitive to losses and potentially more sensitive to unexpected positive outcomes (i.e., "no loss" trials indicate a positive, loss avoidance outcome). Reduced loss sensitivity in youth with $A B$ and $C U$ traits is consistent with behavioral research indicating that individuals with $A B$ and CU/psychopathic traits may overvalue positive feedback (Scerbo et al., 1990), undervalue negative feedback (Blair, Colledge, \& Mitchell, 2001), have difficulty modulating responses in the context of 
reward and punishment (Newman \& Kosson, 1986), and perseverate on previously rewarded stimuli despite increasing punishment (Frick et al., 2003b). The literature on neural response to loss in $A B$ and CU traits in youth is still very limited (Byrd et al., 2014; Dugré et al., 2020). Nevertheless, the current study adds to a growing body of literature implicating blunted loss processing in individuals high on $A B$ and CU traits.

Although $A B$ and $C U$ traits were not directly associated with neural response during loss anticipation, there was a significant interaction of $A B$ and $C U$ traits during loss anticipation. $A B$ was associated with increased reactivity in the precuneus and angular gyrus during loss anticipation in those with higher levels of CU traits but reduced reactivity in those with lower levels of CU traits. These regions are nodes of the default mode network and are typically downregulated during goal-directed activity (Buckner, Andrews-Hanna, \& Schacter, 2008). Previous research indicates that individuals with psychopathic traits have attenuated down-regulation of the default mode network during a go/no-go task (Freeman et al., 2015) and display altered patterns of attention allocation when processing negative information that is secondary to the primary task goals (Baskin-Sommers, Curtin, \& Newman, 2011). Our results suggest that youth with high levels of both $A B$ and $C U$ traits may have reduced task-induced down-regulation of the default mode network during negative anticipatory cues and thus may not allocate attentional resources towards affective information to guide performance. These results also highlight the need to separate anticipatory versus consummatory phases of neural loss processing in $A B$ and CU traits, as we found divergent findings: reduced frontoparietal activity during loss receipt but greater activation of default-mode hubs during loss anticipation.

We found no associations between $A B$ or $C U$ traits and neural response to reward, which is surprising given previous literature linking these traits to reward-related neural dysfunction (Byrd et al., 2014; Murray et al., 2018). However, a recent meta-analysis of youth and adults did not find significant associations between neural reward function and AB (Dugré et al., 2020), though the authors 
emphasized caution given the small number of studies in this area. It is also possible that the pointbased incentive in our version of the MID task may not have been sufficiently stimulating for youth with $A B$ who may require increased sensory input to obtain positive affect (Quay, 1965, 1993).

Although the current study has many strengths, including a large, well-sampled cohort of youth in a narrow age range, the use of multi-method and multi-informant dimensional measures of $A B$ and CU traits, and assessment of anticipation and outcome phases of reward and loss processing, the study has several limitations that should be considered. First, to avoid potential confounding effects in our primarily low-income sample, the MID task provided non-monetary, point-based incentives (instead of money, which may be valued differentially depending on family income). It is possible that the point rewards did not provide the same motivational salience as monetary rewards. Second, we did not record participant responses that occurred outside of the response window. Thus, we were unable to distinguish too-slow responses from non-responses. We addressed this issue by carefully inspecting the data and excluding subjects with inconsistent responding. Nevertheless, we are encouraged that the task main effects (Murray et al., 2020) are consistent with prior meta-analyses of the MID (Dugré, Dumais, Bitar, \& Potvin, 2018; Oldham et al., 2018). Finally, the population-based sampling strategy and dimensional approach for assessing $A B$ and $C U$ traits included a range of youth, from those with no conduct problems to those with clinically significant symptoms of $C D, O D D$, and $C U$ traits. This approach is consistent with dimensional conceptualizations of psychopathology (Blair, 2015a; Insel et al., 2010). However, though several youth did meet diagnostic criteria for AB psychopathology (10 youth had a lifetime diagnosis of $C D$ and/or $O D D$ ), the size of those with full diagnoses was too small to allow for case-control analyses. Our findings may not generalize to samples with more severe $A B$ and will require replication in clinical/forensic samples to determine whether the current associations exist linearly across a wider range of $A B$ and $C U$ traits.

\section{Conclusion}


In a well-sampled cohort of adolescents from medium-sized US cities and primarily low-income environments, $A B$ was associated with decreased frontoparietal response to loss but was not associated with neural response to reward. $C U$ traits moderated associations between $A B$ and loss-related neural functioning, with results being more pronounced in youth with higher levels of CU traits. These results demonstrate that $A B$ is associated with differences in neural circuitry involved in attention, executive control, and behavior modification while processing negative outcomes. Reduced attention and executive control recruitment in response to negative outcomes may contribute to inappropriate costbenefit evaluations and may explain why youth who engage in $A B$ persist in harmful, risky-behaviors despite severe consequences. Improving our understanding of the role of reward and loss-processing in the development and persistence of $\mathrm{AB}$ and $\mathrm{CU}$ traits is key for improving the treatment and prevention of this costly mental illness. 
Table 1: Neural Reactivity during Reward and Loss Processing in Antisocial Behavior and Callous Unemotional Traits

\begin{tabular}{|c|c|c|c|c|}
\hline & $t$ & $\begin{array}{l}\text { Cluster } \\
\text { Size }\end{array}$ & $\begin{array}{c}\text { MNI } \\
\text { Coordinates }\end{array}$ & Brain Region \\
\hline \multicolumn{5}{|c|}{ Reward Anticipation > Reward Outcome } \\
\hline \multicolumn{5}{|c|}{ No significant clusters } \\
\hline \multicolumn{5}{|c|}{ Reward Win> No Win } \\
\hline \multicolumn{5}{|c|}{ No significant clusters } \\
\hline \multicolumn{5}{|c|}{ Loss Anticipation > Loss Outcome } \\
\hline AB x CU Traits & 4.54 & 441 & $30-6440$ & Precuneus, angular gyrus \\
\hline \multicolumn{5}{|c|}{ Loss Outcome $>$ No Loss } \\
\hline \multirow[t]{8}{*}{ AB } & -6.34 & 2732 & -481620 & $\begin{array}{l}\text { Bilateral inferior and middle frontal } \\
\text { gyrus }\end{array}$ \\
\hline & -6.17 & 10030 & $22-6252$ & $\begin{array}{l}\text { Precuneus, bilateral inferior and } \\
\text { superior parietal lobule }\end{array}$ \\
\hline & -5.09 & 599 & 24042 & $\begin{array}{l}\text { Superior frontal gyrus, supplementary } \\
\text { motor area }\end{array}$ \\
\hline & -4.82 & 274 & $-8-346$ & Extra nuclear, vermis \\
\hline & -4.70 & 158 & $58-46-12$ & Inferior and middle temporal gyrus \\
\hline & -4.45 & 697 & $-42-62-14$ & $\begin{array}{l}\text { Fusiform gyrus, lingual gyrus, } \\
\text { cerebellum }\end{array}$ \\
\hline & -4.32 & 176 & $-18-948$ & Middle occipital gyrus \\
\hline & 4.30 & 332 & 181020 & Caudate \\
\hline \multirow[t]{2}{*}{ CU Traits } & -4.23 & 436 & -441840 & Middle frontal gyrus \\
\hline & -3.95 & 186 & $-22-5450$ & Superior parietal lobule \\
\hline \multirow[t]{3}{*}{ AB x CU Traits } & -6.74 & 14315 & -52828 & $\begin{array}{l}\text { Bilateral inferior frontal gyrus, bilateral } \\
\text { superior parietal lobule, anterior } \\
\text { cingulate, precuneus }\end{array}$ \\
\hline & -5.67 & 192 & $56-62-2$ & Right middle and inferior temporal gyrus \\
\hline & -3.93 & 241 & -141438 & Mid-cingulate \\
\hline
\end{tabular}

Note. Associations between $A B$ factor scores, $C U$ traits factor scores, and neural response to reward and loss. All models included age, gender, pubertal status, annual family income, and self-reported race as covariates and were significant at $p<.001$ and $\alpha=.05$., cluster threshold $k=131$. Supplemental analyses of zero-order associations and analyses controlling for the overlap between $A B$ and $C U$ traits were highly similar (Supplemental Table 6). 


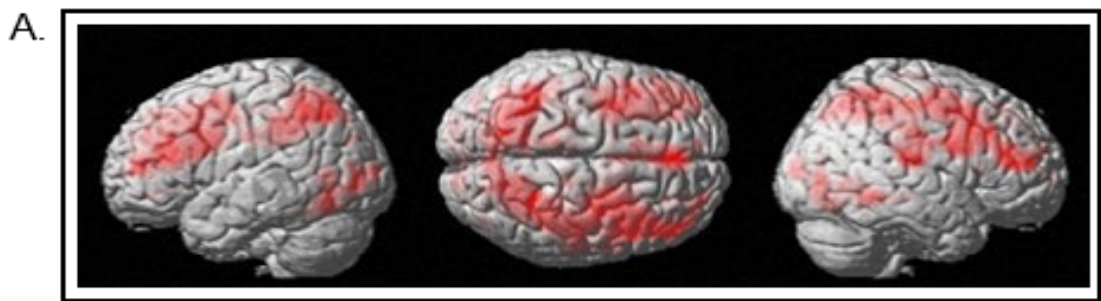

B
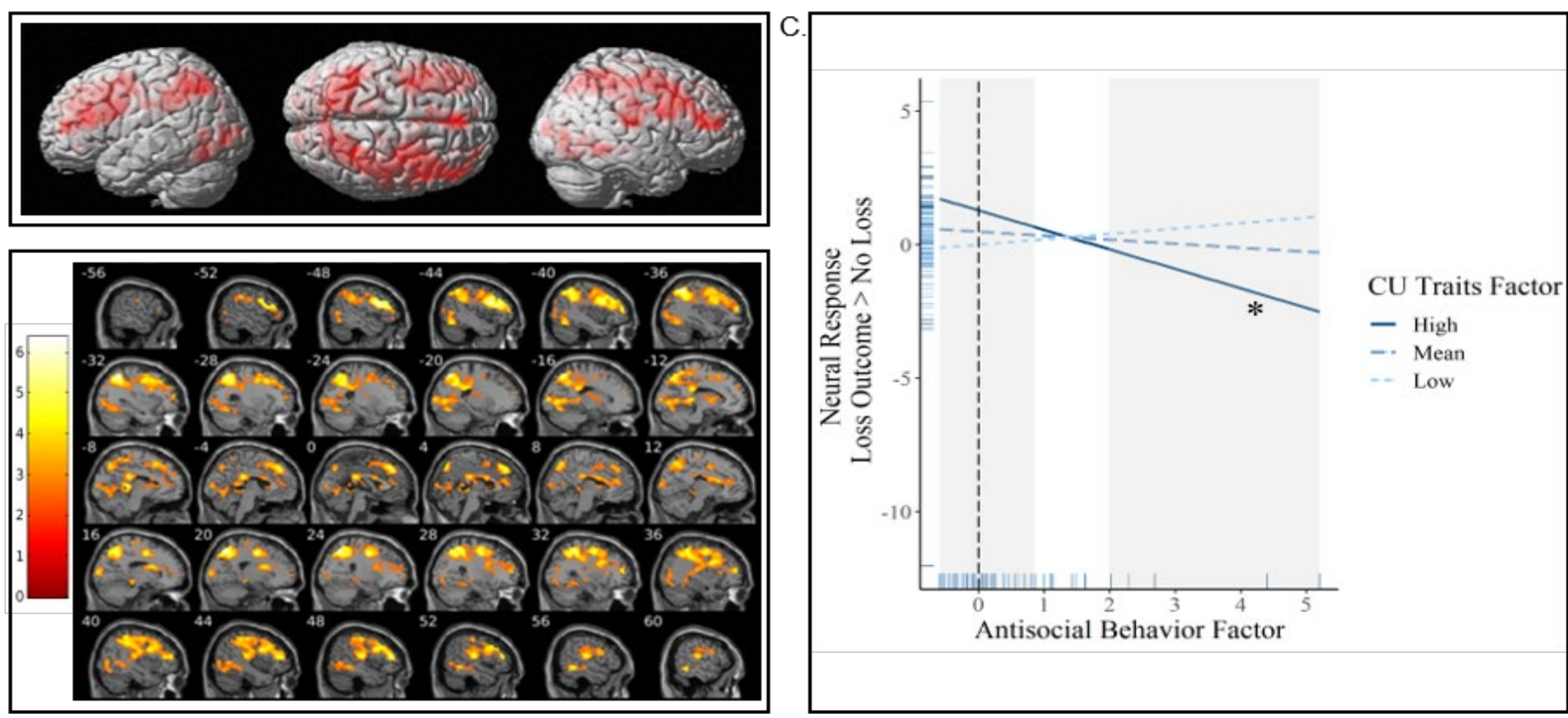

Figure 1. Callous-Unemotional traits Moderate Associations between Antisocial Behavior and Frontoparietal Activation during Loss Outcome. (A) Cortical surface rendering of the association between $A B$ and neural response to Loss Outcome $>$ No Loss. (B). Multi-slice activation map of the association between $A B$ and neural response to Loss Outcome > No Loss. (C) Association between $A B$ and neural response to Loss Outcome $>$ No Loss as a function of CU traits. Mean cluster beta-weights were extracted at from main cluster encompassing bilateral inferior frontal gyri and superior parietal lobules $(t=-6.74, k=14315, \mathrm{MNI}: \mathrm{x}=-52 \mathrm{y}=8 \mathrm{z}=28$ ). Simple slopes plotted at mean, high, and low levels $\mathrm{CU}$ traits, asterisk indicates significant slope at high level of CU traits $p=<.001$. High CU traits was coded as + 1SD from the CU traits factor mean, whereas low was coded as the lower bound of the $\mathrm{CU}$ traits factor due to there being no subjects 1 SD below the mean. The grey area indicates the level of $A B$ at which the association is significant ( $A B$ factor score $<0.85$ and $>1.99$ ). 


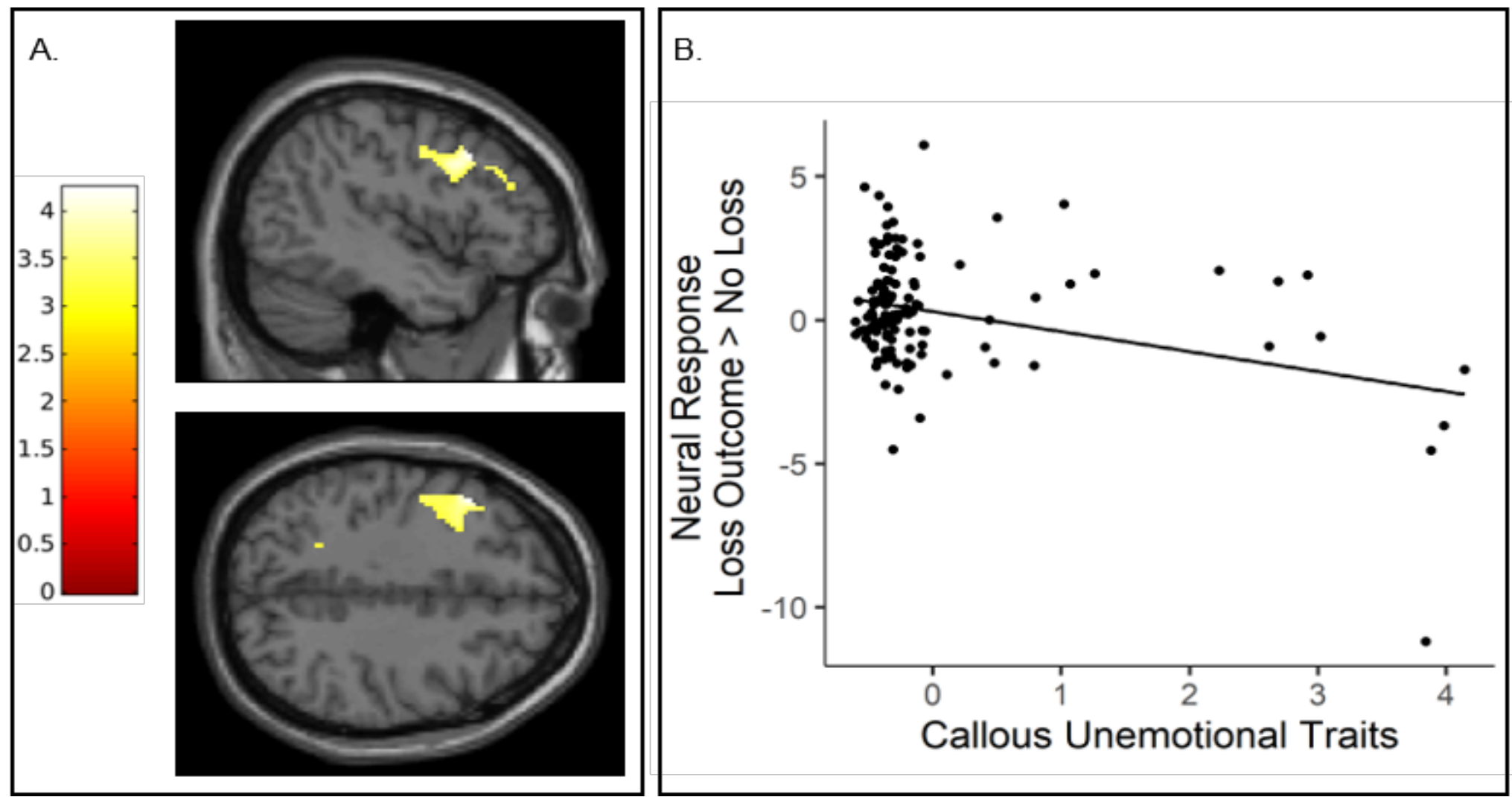

Figure 2. Callous-Unemotional Traits are Associated with Reduced Middle Frontal Gyrus Activity during Loss Outcome. (A) The CU traits factor score was associated with reduced response in the middle frontal gyrus during Loss Anticipation > Loss Outcome (centered at peak voxel MNI: $\mathrm{x}=-44 \mathrm{y}=18 \mathrm{z}=40 ; t=4.23, k=436$ ). (B) Scatterplot of association between CU traits and neural response to Loss Outcome $>$ No Loss. 


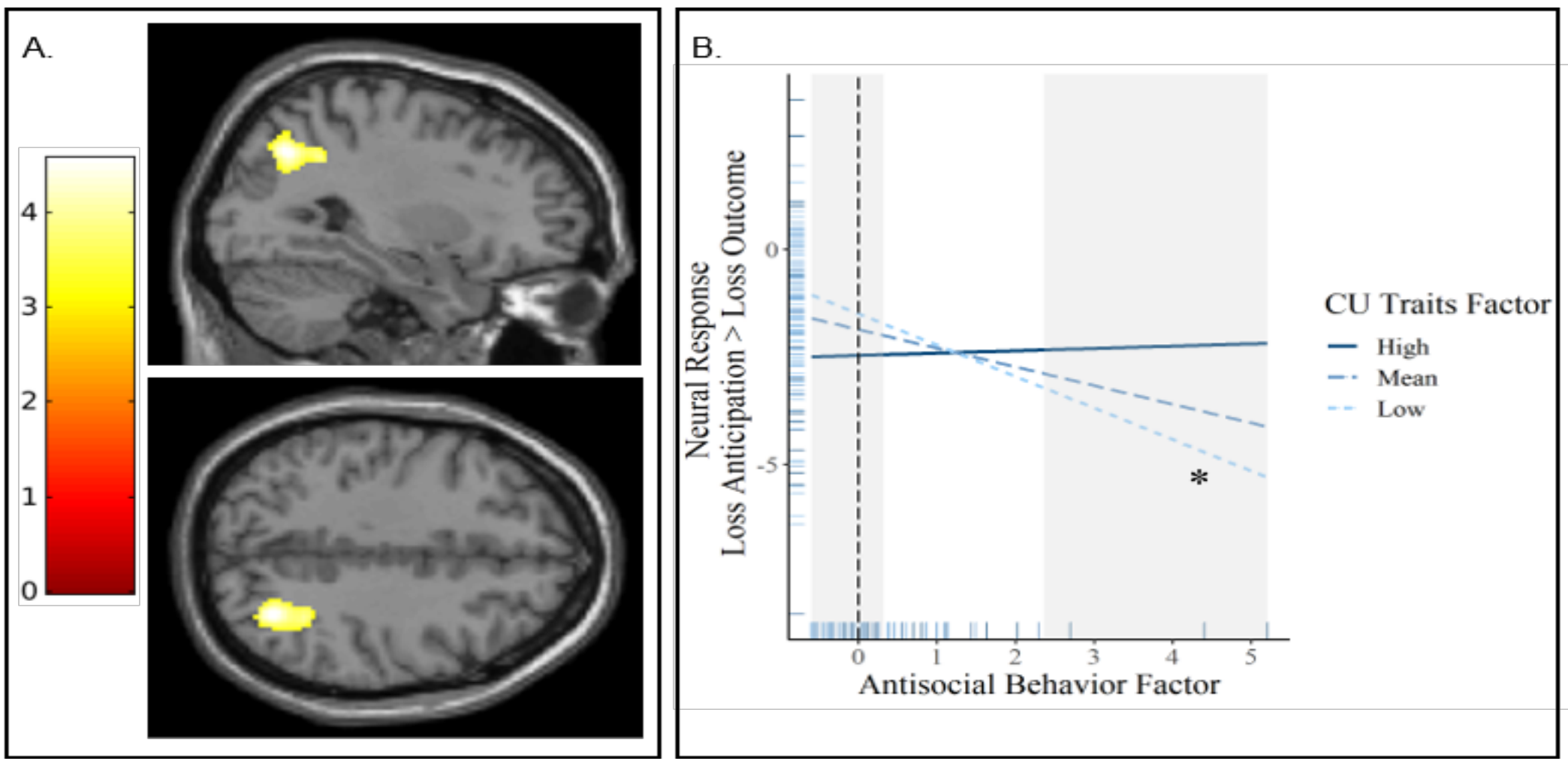

Figure 3. Callous-Unemotional traits Moderate Associations between Antisocial Behavior Angular Gyrus Activation during Loss Anticipation. (A) $C U$ traits significantly moderated the association between $A B$ and neural response in the angular gyrus and precuneus during Loss Anticipation > Loss Outcome (centered at peak voxel MNI: $x=30 y=-64 z=40 ; t=4.54, k=441$ ). (B) Association between $A B$ and neural response to Loss Anticipation > Loss Outcome as a function of CU traits. Mean cluster beta-weights were extracted at from angular gyrus/precuneus cluster $(t=4.54, k=441, \mathrm{MNI}: \mathrm{x}=30 \mathrm{y}=-64 \mathrm{z}=40)$. Simple slopes plotted at mean, high, and low levels CU traits, asterisk indicates significant slope at low level of CU traits $p=.04$. High CU traits was coded as + 1SD from the CU traits factor mean, whereas low was coded as the lower bound of the CU traits factor due to there being no subjects 1 SD below the mean. The grey area indicates the level of $A B$ at which the association is significant ( $A B$ factor score $<0.32$ and $>2.36$ ). 


\section{References}

Achenbach, T. M. (1991). Integrative guide for the 1991 CBCL/4-18, YSR, and TRF profiles: Department of Psychiatry, University of Vermont.

Achenbach, T. M., Dumenci, L., \& Rescorla, L. A. (2003). DSM-oriented and empirically based approaches to constructing scales from the same item pools. Journal of clinical child and adolescent psychology, 32(3), 328-340.

American Psychiatric Association. (2013). Diagnostic and Statistical Manual of Mental Disorders, Fifth Edition (DSM-5). Washington, DC: American Psychiatric Association.

Baskin-Sommers, A. R., Curtin, J. J., \& Newman, J. P. (2011). Specifying the attentional selection that moderates the fearlessness of psychopathic offenders. Psychological Science, 22(2), 226-234.

Berridge, K. C., \& Robinson, T. E. (2003). Parsing reward. Trends in neurosciences, 26(9), 507-513.

Bjork, J. M., Chen, G., Smith, A. R., \& Hommer, D. W. (2010). Incentive-elicited mesolimbic activation and externalizing symptomatology in adolescents. Journal of Child Psychology and Psychiatry, 51(7), 827-837. doi:10.1111/j.1469-7610.2009.02201.x. PMCID: PMC2915786

Blair, R., Colledge, E., \& Mitchell, D. (2001). Somatic markers and response reversal: is there orbitofrontal cortex dysfunction in boys with psychopathic tendencies? Journal of abnormal child psychology, 29(6), 499-511.

Blair, R. J. R. (2015a). Psychopathic traits from an RDoC perspective. Current Opinion in Neurobiology, 30, 79-84. doi:http://dx.doi.org/10.1016/j.conb.2014.09.011.

Blair, R. J. R. (2015b). Reward Processing, Functional Connectivity, Psychopathy, and Research Domain Criteria. Biological Psychiatry, 78(9), 592-593.

Buckholtz, J. W., Treadway, M. T., Cowan, R. L., Woodward, N. D., Benning, S. D., Li, R., . . Zald, D. H. (2010). Mesolimbic dopamine reward system hypersensitivity in individuals with psychopathic traits. Nat Neurosci, 13(4), 419-421. doi:10.1038/nn.2510. PMCID: PMC2916168

Buckner, R. L., Andrews-Hanna, J. R., \& Schacter, D. L. (2008). The brain's default network: anatomy, function, and relevance to disease. Annals of the New York Academy of Sciences, 1124, 1-38.

Budhani, S., \& Blair, R. J. R. (2005). Response reversal and children with psychopathic tendencies: success is a function of salience of contingency change. Journal of Child Psychology and Psychiatry, 46(9), 972-981. PMCID: 16109000

Burch, T. (2015). Skin color and the criminal justice system: Beyond black-white disparities in sentencing. Journal of Empirical Legal Studies, 12(3), 395-420.

Button, K. S., loannidis, J. P., Mokrysz, C., Nosek, B. A., Flint, J., Robinson, E. S., \& Munafò, M. R. (2013). Power failure: why small sample size undermines the reliability of neuroscience. Nature Reviews Neuroscience, 14(5), 365-376.

Byrd, A. L., Hawes, S. W., Burke, J. D., Loeber, R., \& Pardini, D. A. (2018). Boys with conduct problems and callous-unemotional traits: neural response to reward and punishment and associations with treatment response. Developmental cognitive neuroscience, 30, 51-59.

Byrd, A. L., Loeber, R., \& Pardini, D. A. (2014). Antisocial behavior, psychopathic features and abnormalities in reward and punishment processing in youth. Clin Child Fam Psychol Rev, 17(2), 125-156. doi:10.1007/s10567-013-0159-6. PMCID: 24357109

Chiao, J. Y. (2009). Cultural neuroscience: A once and future discipline. Progress in brain research, 178, 287-304.

Chiao, J. Y., \& Cheon, B. K. (2010). The weirdest brains in the world. Behavioral and brain sciences, 33(23), 88-90.

Cohn, M. D., Veltman, D. J., Pape, L. E., van Lith, K., Vermeiren, R. R., van den Brink, W., ... Popma, A. (2015). Incentive Processing in Persistent Disruptive Behavior and Psychopathic Traits: A 
Functional Magnetic Resonance Imaging Study in Adolescents. Biol Psychiatry. doi:10.1016/j.biopsych.2014.08.017.

Cox, R. W., Chen, G., Glen, D. R., Reynolds, R. C., \& Taylor, P. A. (2017). FMRI Clustering in AFNI: FalsePositive Rates Redux. Brain connectivity, 7(3), 152-171. doi:10.1089/brain.2016.0475.

Crowley, T. J., Dalwani, M. S., Mikulich-Gilbertson, S. K., Du, Y. P., Lejuez, C. W., Raymond, K. M., \& Banich, M. T. (2010). Risky decisions and their consequences: neural processing by boys with antisocial substance disorder. PloS one, 5(9), e12835.

Dixon, M. L., \& Christoff, K. (2012). The decision to engage cognitive control is driven by expected reward-value: neural and behavioral evidence. PloS one, 7(12), e51637-e51637. doi:10.1371/journal.pone.0051637.

Dixon, M. L., De La Vega, A., Mills, C., Andrews-Hanna, J., Spreng, R. N., Cole, M. W., \& Christoff, K. (2018). Heterogeneity within the frontoparietal control network and its relationship to the default and dorsal attention networks. Proceedings of the National Academy of Sciences, 201715766.

Dotterer, H. L., Waller, R., Hein, T. C., Pardon, A., Mitchell, C., Lopez-Duran, N., . . Hyde, L. W. (2020). Clarifying the Link Between Amygdala Functioning During Emotion Processing and Antisocial Behaviors Versus Callous-Unemotional Traits Within a Population-Based Community Sample. Clinical Psychological Science, 8(5), 918-935. doi:10.1177/2167702620922829.

Dugré, J. R., Dumais, A., Bitar, N., \& Potvin, S. (2018). Loss anticipation and outcome during the Monetary Incentive Delay Task: a neuroimaging systematic review and meta-analysis. PeerJ, 6 , e4749.

Dugré, J. R., Radua, J., Carignan-Allard, M., Dumais, A., Rubia, K., \& Potvin, S. (2020). Neurofunctional abnormalities in antisocial spectrum: A meta-analysis of $\mathrm{fMRI}$ studies on Five distinct neurocognitive research domains. Neuroscience \& Biobehavioral Reviews, 119, 168-183. doi:https://doi.org/10.1016/j.neubiorev.2020.09.013.

Elliott, D., Huizinga, D., \& Ageton, S. (1985). Explaining delinquency and drug use. Beverly Hills, CA: Sage Publications.

Falk, E. B., Hyde, L. W., Mitchell, C., Faul, J., Gonzalez, R., Heitzeg, M. M., . . Maslowsky, J. (2013). What is a representative brain? Neuroscience meets population science. Proceedings of the National Academy of Sciences, 110(44), 17615-17622.

Finger, E. C., Marsh, A. A., Blair, K. S., Reid, M. E., Sims, C., Ng, P., . . Blair, R. J. R. (2011). Disrupted reinforcement signaling in the orbitofrontal cortex and caudate in youths with conduct disorder or oppositional defiant disorder and a high level of psychopathic traits. American Journal of Psychiatry.

Foster, E. M., \& Jones, D. E. (2005). The high costs of aggression: public expenditures resulting from conduct disorder. AMERICAN JOURNAL OF PUBLIC HEALTH, 95(10), 1767-1772. doi:10.2105/ajph.2004.061424. PMCID: PMC1449434

Fowles, D. C. (1980). The three arousal model: Implications of Gray's two-factor learning theory for heart rate, electrodermal activity, and psychopathy. Psychophysiology, 17(2), 87-104. PMCID: 6103567

Freeman, S. M., Clewett, D. V., Bennett, C. M., Kiehl, K. A., Gazzaniga, M. S., \& Miller, M. B. (2015). The posteromedial region of the default mode network shows attenuated task-induced deactivation in psychopathic prisoners. Neuropsychology, 29(3), 493.

Frick, P. J. (2004). The inventory of callous-unemotional traits. Unpublished rating scale.

Frick, P. J. (2016). Clinical assessment of prosocial emotions, version 1.1 (CAPE 1.1). Unpublished measure. Louisiana State University.

Frick, P. J., Cornell, A. H., Barry, C. T., Bodin, S. D., \& Dane, H. E. (2003a). Callous-unemotional traits and conduct problems in the prediction of conduct problem severity, aggression, and self-report of delinquency. Journal of abnormal child psychology, 31(4), 457-470. 
Frick, P. J., Cornell, A. H., Bodin, S. D., Dane, H. E., Barry, C. T., \& Loney, B. R. (2003b). Callousunemotional traits and developmental pathways to severe conduct problems. Developmental psychology, 39(2), 246.

Gatzke-Kopp, L. M., Beauchaine, T. P., Shannon, K. E., Chipman, J., Fleming, A. P., Crowell, S. E., . . . Aylward, E. (2009). Neurological correlates of reward responding in adolescents with and without externalizing behavior disorders. Journal of Abnormal Psychology, 118(1), 203.

Gregory, S., Blair, R. J., Simmons, A., Kumari, V., Hodgins, S., \& Blackwood, N. (2015). Punishment and psychopathy: a case-control functional MRI investigation of reinforcement learning in violent antisocial personality disordered men. The Lancet Psychiatry, 2(2), 153-160.

Haber, S. N., \& Knutson, B. (2010). The reward circuit: linking primate anatomy and human imaging. Neuropsychopharmacology, 35(1), 4-26.

Heekeren, H. R., Wartenburger, I., Marschner, A., Mell, T., Villringer, A., \& Reischies, F. M. (2007). Role of ventral striatum in reward-based decision making. Neuroreport, 18(10), 951-955. doi:10.1097/WNR.0b013e3281532bd7.

Hoppenbrouwers, S. S., Neumann, C. S., Lewis, J., \& Johansson, P. (2015). A latent variable analysis of the Psychopathy Checklist-Revised and behavioral inhibition system/behavioral activation system factors in North American and Swedish offenders. Personality Disorders: Theory, Research, and Treatment, 6(3), 251.

Hyde, L. W., Tompson, S., Creswell, J. D., \& Falk, E. B. (2015). Cultural neuroscience: new directions as the field matures. Culture and Brain, 3(2), 75-92.

Insel, T., Cuthbert, B., Garvey, M., Heinssen, R., Pine, D. S., Quinn, K., . . W Wang, P. (2010). Research domain criteria (RDoC): toward a new classification framework for research on mental disorders: Am Psychiatric Assoc.

Kaufman, J., Birmaher, B., Brent, D., Rao, U., Flynn, C., Moreci, P., . . Ryan, N. (1997). Schedule for affective disorders and schizophrenia for school-age children-present and lifetime version (KSADS-PL): initial reliability and validity data. Journal of the American Academy of Child \& Adolescent Psychiatry, 36(7), 980-988. PMCID: 9204677

Knutson, B., \& Greer, S. M. (2008). Anticipatory affect: neural correlates and consequences for choice. Philos Trans R Soc Lond B Biol Sci, 363(1511), 3771-3786. doi:10.1098/rstb.2008.0155. PMCID: PMC2607363

Krueger, R. F., Markon, K. E., Patrick, C. J., Benning, S. D., \& Kramer, M. D. (2007). Linking antisocial behavior, substance use, and personality: an integrative quantitative model of the adult externalizing spectrum. Journal of Abnormal Psychology, 116(4), 645.

Leventhal, T., \& Brooks-Gunn, J. (2000). The neighborhoods they live in: the effects of neighborhood residence on child and adolescent outcomes. Psychological bulletin, 126(2), 309.

Lin, H.-Y., Tseng, W.-Y. I., Lai, M.-C., Matsuo, K., \& Gau, S. S.-F. (2015). Altered resting-state frontoparietal control network in children with attention-deficit/hyperactivity disorder. Journal of the International Neuropsychological Society, 21(4), 271-284.

Matthys, W., Van Goozen, S. H., Snoek, H., \& Van Engeland, H. (2004). Response perseveration and sensitivity to reward and punishment in boys with oppositional defiant disorder. European Child \& Adolescent Psychiatry, 13(6), 362-364. PMCID: 15619048

Murray, L., Lopez-Duran, N. L., Mitchell, C., Monk, C. S., \& Hyde, L. W. (2020). Neural mechanisms of reward and loss processing in a low-income sample of at-risk adolescents. Social cognitive and affective neuroscience, 15(12), 1310-1325. doi:10.1093/scan/nsaa157 \%J Social Cognitive and Affective Neuroscience.

Murray, L., Shaw, D. S., Forbes, E. E., \& Hyde, L. W. (2017). Reward-Related Neural Correlates of Antisocial Behavior and Callous-Unemotional Traits in Young Men. Biological Psychiatry: Cognitive Neuroscience and Neuroimaging, 2(4), 346-354. PMCID: PMC5606223 
Murray, L., Waller, R., \& Hyde, L. W. (2018). A systematic review examining the link between psychopathic personality traits, antisocial behavior, and neural reactivity during reward and loss processing. Personality Disorders: Theory, Research, Treatment, 9(6), 497.

Muthén, L. K., \& Muthén, B. O. (2014). Mplus 7.3. Los Angeles, CA: Muthén \& Muthén.

Newman, J. P., \& Kosson, D. S. (1986). Passive avoidance learning in psychopathic and nonpsychopathic offenders. Journal of Abnormal Psychology, 95(3), 252. PMCID: 3745647

Newman, J. P., Widom, C. S., \& Nathan, S. (1985). Passive avoidance in syndromes of disinhibition: Psychopathy and extraversion. Journal of personality and social psychology, 48(5), 1316.

Oldham, S., Murawski, C., Fornito, A., Youssef, G., Yücel, M., \& Lorenzetti, V. (2018). The anticipation and outcome phases of reward and loss processing: A neuroimaging meta-analysis of the monetary incentive delay task. Human brain mapping.

Petersen, A. C., Crockett, L., Richards, M., \& Boxer, A. (1988). A self-report measure of pubertal status: Reliability, validity, and initial norms. Journal of Youth and Adolescence, 17(2), 117-133.

Phinney, J. S. (2010). Multigroup Ethnic Identity Measure (MEIM) Encyclopedia of Cross-Cultural School Psychology (pp. 642-643): Springer.

Quay, H. C. (1965). Psychopathic personality as pathological stimulation-seeking. American Journal of Psychiatry, 122(2), 180-183. PMCID: 14313433

Quay, H. C. (1993). The psychobiology of undersocialized aggressive conduct disorder: A theoretical perspective. Development and psychopathology, 5(1-2), 165-180.

Reichman, N. E., Teitler, J. O., Garfinkel, I., \& McLanahan, S. S. (2001). Fragile families: Sample and design. Children and Youth Services Review, 23(4-5), 303-326.

Scerbo, A., Raine, A., O'Brien, M., Chan, C.-J., Rhee, C., \& Smiley, N. (1990). Reward dominance and passive avoidance learning in adolescent psychopaths. Journal of abnormal child psychology, 18(4), 451-463.

Schwenck, C., Ciaramidaro, A., Selivanova, M., Tournay, J., Freitag, C. M., \& Siniatchkin, M. (2017). Neural correlates of affective empathy and reinforcement learning in boys with conduct problems: fMRI evidence from a gambling task. Behavioural brain research, 320, 75-84.

Seeley, W. W., Menon, V., Schatzberg, A. F., Keller, J., Glover, G. H., Kenna, H., . . Greicius, M. D. (2007). Dissociable intrinsic connectivity networks for salience processing and executive control. Journal of Neuroscience, 27(9), 2349-2356.

Shaw, D. S., Hyde, L. W., \& Brennan, L. M. (2012). Early predictors of boys' antisocial trajectories. Dev Psychopathol, 24(3), 871-888. doi:10.1017/s0954579412000429. PMCID: PMC3409584

Veroude, K., von Rhein, D., Chauvin, R. J., van Dongen, E. V., Mennes, M. J., Franke, B., . . Hoekstra, P. J. (2016). The link between callous-unemotional traits and neural mechanisms of reward processing: An fMRI study. Psychiatry Research: Neuroimaging, 255, 75-80.

Walker, T. M., Frick, P. J., Matlasz, T. M., Robertson, E. L., Mikolajewski, A. J., Mitchell, C., ... Hyde, L. W. J. A. (2020). Psychometric Properties of a Semistructured Interview to Assess Limited Prosocial Emotions. 1073191120947796.

White, S. F., Pope, K., Sinclair, S., Fowler, K. A., Brislin, S. J., Williams, W. C., . . Blair, R. J. R. (2013). Disrupted expected value and prediction error signaling in youths with disruptive behavior disorders during a passive avoidance task. American Journal of Psychiatry. 


\section{Supplemental Information}

\section{Figure 1}

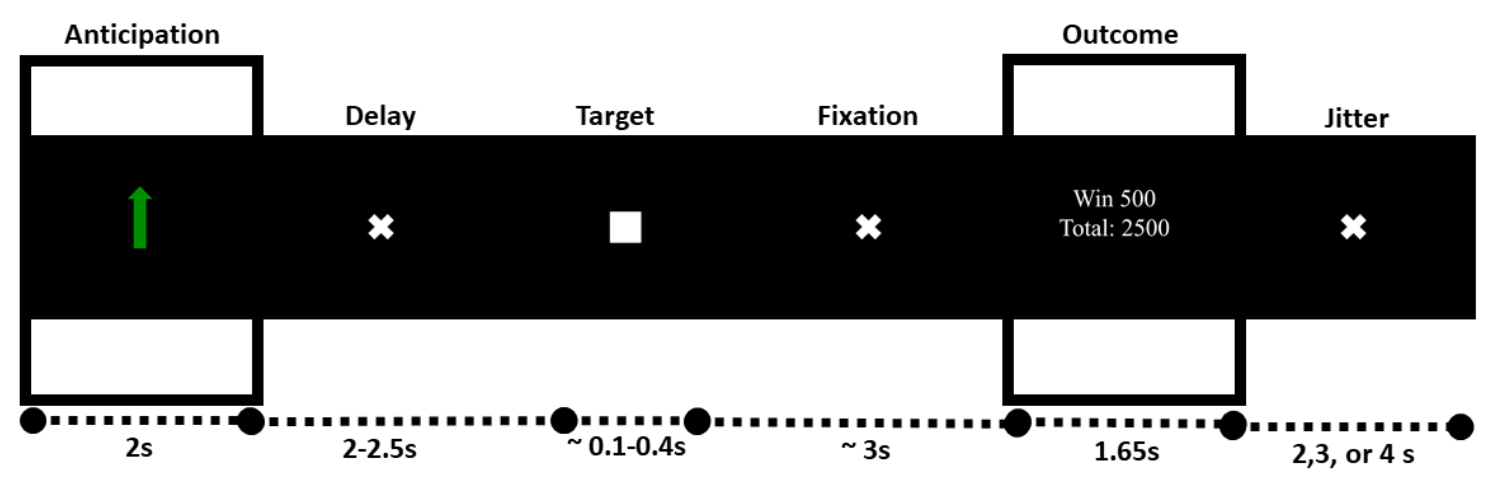

Modified Monetary Incentive Delay task. A schematic of a single MID trial. Trial type was indicated by a up arrow, down arrow or a horizontal double arrow to indicate reward, loss and neutral trials, respectively ( $2 \mathrm{~s})$. After a variable delay (2-2.5 s) a white square (target) appeared. Participants were instructed to respond as quickly as possible to the target. A fixation cross appeared that included a delay $(2 \mathrm{~s})$ and a catch-up period to account for variability in participant response. Feedback was presented (1.65 s), followed by a jittered inter-trial interval $(2,3$ or $4 \mathrm{~s})$. The task was modified from common versions of the MID (e.g., Casey et al., 2018; Knutson, Fong, Adams, Varner, \& Hommer, 2001) by adding a jittered intertrial interval to allow for more temporal separation of anticipation and consumption phases of reward and loss processing. Figure reproduced, with permission from (Murray, Lopez-Duran, Mitchell, Monk, \& Hyde, 2020). 
Supplemental Table 1: Summary of Available Data for Analyses

\begin{tabular}{lcc}
\hline & Number lost & $\begin{array}{c}\text { Participants } \\
\text { with data }\end{array}$ \\
\hline Original sample & $\mathbf{2 3 7}$ \\
\hline Sample with imaging data & & \\
& & \\
- Refused MRI & 5 \\
- Exceeded MRI table weight limit/couldn't fit in scanner & 3 \\
- Medical restriction & 13 \\
- Braces or other metal in body & 1 \\
- Risk of pregnancy & 1 & \\
- Missed scanning appointment & 2 & \\
- Excluded for diagnosis of Autism Spectrum Disorder & 12 & \\
- Incomplete fMRI data & & $\mathbf{1 9 3}$ \\
\hline Total lost & $\mathbf{4 4}$
\end{tabular}

Sample with usable imaging data

- $\quad$ Task administration issue (i.e., wrong version, wrong hand)

- $\quad f M R I$ scan quality issues (distortion, artifact, signal drop out)

- $\quad$ Low ventral striatum coverage $(<70 \%)$

- Motion outlier ( $>20 \%$ TRs with ART)

- Poor Task Performance (<6 trials per outcome condition) 26

- Poor Task Performance (>10 consecutive trials without a 6 recorded button press)

- Activation outlier

6

Total lost

65

128

Note. Participants with complete and usable MRI data from the full sample. Consistent with previous work in this sample (Murray et al., 2020), fMRI data were excluded if there was signal drop out in the VS $\mathrm{ROI}(<70 \%$ coverage) or in reward-related limbic and prefrontal regions via visual inspection of individual whole brain maps. Six subjects were identified with large outlier parameter estimates $( \pm>3$ s.d. from sample mean) in contrasts of interest. For these participants, individual functional scans were further inspected to confirm either a few large or many small movements that caused abnormal parameter estimates. Analyses including these subjects is presented in Supplemental Table 5. Behavioral data from the MID task were analyzed to ensure sufficient responding during the task. Youth with $<6$ trials of each outcome were excluded due to poor task responding. Also, for participants with $<10$ trials per outcome, behavioral data were visually inspected to ensure consistent participant engagement. 
Supplemental Table 2: Descriptive Statistics of Demographic Measures for the Final Analytic Sample

\begin{tabular}{lc}
\hline Measure & Count (\%) \\
\hline Adolescent Gender & $54(42.2)$ \\
$-\quad$ Male & $74(57.8)$ \\
$-\quad$ Female & \\
\hline Adolescent Self-Reported Race & $97(75.8)$ \\
$-\quad$ Black / African American & $15(11.7)$ \\
$-\quad$ White / Caucasian & $5(3.9)$ \\
$-\quad$ More than one race & $5(3.9)$ \\
$-\quad$ Other Non-Hispanic Groups & \\
\hline Adolescent Self-Reported Ethnicity & $122(95.3)$ \\
$-\quad$ Not Hispanic & $6(4.7)$ \\
\hline Hispanic & Range \\
\hline Measure & Mean (SD) \\
- Age (Years) & $15.0-17.6$ \\
&
\end{tabular}


Supplemental Table 3: Descriptive Statistics and Bivariate Correlations between Measures Included in Antisocial Behavior Factor Score

\begin{tabular}{|c|c|c|c|c|}
\hline & $\begin{array}{c}\text { CBCL } \\
\text { Aggression }\end{array}$ & $\begin{array}{c}\text { CBCL } \\
\text { Rule-Breaking }\end{array}$ & SRD Total Score & $\begin{array}{c}\text { KSADS } \\
\text { ODD/CD } \\
\text { Symptoms }\end{array}$ \\
\hline CBCL Rule-Breaking & $.81 * * *$ & & & \\
\hline $\begin{array}{l}\text { SRD Total Score } \\
\text { (no drug items) }\end{array}$ & $.39 * * *$ & $.30 * * *$ & & \\
\hline $\begin{array}{l}\text { KSADS ODD/CD Symptom } \\
\text { Count }\end{array}$ & $.64 * * *$ & $.61 * * *$ & $.47^{* * *}$ & \\
\hline$M(S D)$ & $3.84(2.82)$ & $2.00(4.79)$ & $5.77(6.88)$ & $4.85(9.04)$ \\
\hline Range & $0-25$ & $0-18$ & $0-44$ & $0-51$ \\
\hline Factor Loading & $.88^{* * *}$ & $.93^{* * *}$ & $.39 * * *$ & $.69 * * *$ \\
\hline \multicolumn{5}{|c|}{$\begin{array}{l}\text { Note. }{ }^{\dagger} \mathrm{p}<.10,{ }^{*} \mathrm{p}<.05 ;{ }^{* *} \mathrm{p}<.01 ;{ }^{* * *} \mathrm{p}<.001 . \mathrm{CBCL}=\text { Child Behavior Checklist; SRD = Self-Report of } \\
\text { Delinquency; KSADS = Kiddie Schedule for Affective Disorders and Schizophrenia; ODD = oppositional } \\
\text { defiant disorder; CD = conduct disorder; } \mathrm{df}=\text { degrees of freedom; TLI = Tucker-Lewis index; CFI = } \\
\text { comparative fit index; RMSEA = root mean square error of approximation; SRMR = standardized root } \\
\text { mean residual. Correlations were computed for whole sample ( } \mathrm{n}=237 \text { ). Analyses performed using } \\
\text { maximum likelihood estimation with robust standard errors (which can accommodate skewness) in } \\
\text { Mplus version } 7.3 \text { (Muthén \& Muthén, 2014). Chi-Square test of model fit = } 2.67, d f=1, p=.10 ; C F I=.99, \\
\text { TLI=.96, RMSEA=.08, SRMR=.01. Based on modification indices, two scales' residuals (SRD Total score } \\
\text { and KSADS ODD/CD Symptom Count) were allowed to correlate. }\end{array}$} \\
\hline
\end{tabular}


Supplemental Table 4: Descriptive Statistics and Bivariate Correlations between Measures Included in Callous-Unemotional Traits Factor Score

\begin{tabular}{|c|c|c|c|}
\hline & ICU Parent Total & $\begin{array}{c}\text { ICU } \\
\text { Self } \\
\text { Total }\end{array}$ & $\begin{array}{c}\text { Limited Prosocial } \\
\text { Emotions } \\
\text { Symptoms }\end{array}$ \\
\hline \multicolumn{4}{|l|}{ ICU Parent-Report Total Score } \\
\hline ICU Self-Report Total Score & $.13^{*}$ & & \\
\hline $\begin{array}{l}\text { CAPE/KSADS Limited Prosocial } \\
\text { Emotions Symptom Count }\end{array}$ & $.35 * * *$ & $.29 * * *$ & \\
\hline$M(S D)$ & 18.99(8.99) & $21.78(8.24)$ & $.97(2.69)$ \\
\hline Range & $1-52$ & $4-44$ & $0-16$ \\
\hline Factor Loading & $.40 * * *$ & $.35 * * *$ & $.86^{* * *}$ \\
\hline \multicolumn{4}{|c|}{$\begin{array}{l}\text { Note. }{ }^{\dagger} \mathrm{p}<.10,{ }^{*} \mathrm{p}<.05 ;{ }^{* *} \mathrm{p}<.01 ;{ }^{* * *} \mathrm{p}<.001 . \mathrm{ICU}=\text { Inventory of Callous-Unemotional Traits; KSADS = } \\
\text { Kiddie Schedule for Affective Disorders and Schizophrenia; CAPE = Clinical Assessment of Prosocial } \\
\text { Emotions; df = degrees of freedom; TLI = Tucker-Lewis index; CFI = comparative fit index; RMSEA = root } \\
\text { mean square error of approximation; SRMR = standardized root mean residual. Consistent with prior } \\
\text { studies that have used the ICU, we used a total score for } 22 \text { of the original } 24 \text { items dropping two items } \\
\text { based on an examination of polychoric inter-item correlations (Waller et al., 2015). Correlations were } \\
\text { computed for whole sample ( } \mathrm{n}=237 \text { ). Measures of CU traits were significantly skewed. Analyses } \\
\text { performed using maximum likelihood estimation with robust standard errors (which can accommodate } \\
\text { skewness) in Mplus version } 7.3 \text { (Muthén \& Muthén, 2014). Model was fully saturated. }\end{array}$} \\
\hline
\end{tabular}


Supplemental Table 5: Neural Reactivity during Reward and Loss Processing in Antisocial Behavior and Callous Unemotional Traits with fMRI Outliers Included

\begin{tabular}{|c|c|c|c|c|}
\hline & $t$ & $\begin{array}{c}\text { Cluster } \\
\text { Size }\end{array}$ & $\begin{array}{c}\text { MNI } \\
\text { Coordinates }\end{array}$ & Brain Region \\
\hline \multicolumn{5}{|c|}{ Loss Anticipation > Loss Outcome } \\
\hline \multicolumn{5}{|c|}{ No significant clusters } \\
\hline \multicolumn{5}{|c|}{ Reward Win $>$ No Win } \\
\hline \multicolumn{5}{|c|}{ No significant clusters } \\
\hline \multicolumn{5}{|c|}{ Loss Anticipation > Loss Outcome } \\
\hline AB x CU Traits & 4.54 & 441 & $30-6440$ & Precuneus, angular gyrus \\
\hline \multicolumn{5}{|c|}{ Loss Outcome $>$ No Loss } \\
\hline \multirow[t]{7}{*}{ AB } & -5.67 & 1265 & $30-5060$ & Superior parietal lobule \\
\hline & -5.33 & 1468 & $-34-5656$ & Inferior parietal lobule \\
\hline & -5.08 & 345 & 484014 & Inferior frontal gyrus \\
\hline & -4.58 & 613 & $32-860$ & Superior and middle frontal gyrus \\
\hline & -4.43 & 272 & $-4-3024$ & Posterior cingulate \\
\hline & -4.09 & 168 & 4422 & Caudate \\
\hline & -3.64 & 235 & -523216 & Inferior frontal gyrus \\
\hline \multirow[t]{2}{*}{ AB x CU Traits } & -6.32 & 1323 & $-20-6658$ & Bilateral superior parietal lobule \\
\hline & -5.19 & 2006 & 03614 & Anterior cingulate, middle frontal gyrus \\
\hline
\end{tabular}

Note. Associations between $\mathrm{AB}$ and $\mathrm{CU}$ traits factors and neural response to reward and loss including fMRI outliers. Six youths were excluded from the analyses due to excessive movement-related signal artifacts that could potentially influence the findings. Analyses including these subjects (total $n=134$ ) controlled for demographic variables (age, gender, pubertal status, annual family income, self-reported race) and were significant at $p<.001$ and $\alpha=.05$., cluster threshold $k=131$.and were largely similar to those reported in the main text and showed reduced frontoparietal activity to loss outcome $>$ no loss in $A B$ that was also moderated by $C U$ traits. However, the association between $C U$ traits and neural response to Loss Outcome $>$ No Loss and the interaction of $A B$ and $C U$ traits to Loss Anticipation > Loss Outcome were not significant with the outliers included. 
Supplemental Table 6: Neural Reactivity during Reward and Loss Processing in Antisocial Behavior and Callous Unemotional Traits

\begin{tabular}{|c|c|c|c|c|}
\hline & $\boldsymbol{t}$ & $\begin{array}{l}\text { Cluster } \\
\text { Size }\end{array}$ & $\begin{array}{c}\text { MNI } \\
\text { Coordinates }\end{array}$ & Brain Region \\
\hline \multicolumn{5}{|c|}{ Reward Anticipation > Reward Outcome } \\
\hline \multicolumn{5}{|c|}{ No significant clusters } \\
\hline \multicolumn{5}{|c|}{ Reward Win> No Win } \\
\hline \multicolumn{5}{|c|}{ No significant clusters } \\
\hline \multicolumn{5}{|c|}{ Loss Anticipation > Loss Outcome } \\
\hline $\begin{array}{l}\text { AB } \times \text { CU Traits } \\
\text { (no covariates) }\end{array}$ & 4.43 & 391 & $30-6642$ & Precuneus, angular gyrus \\
\hline \multicolumn{5}{|c|}{ Loss Outcome $>$ No Loss } \\
\hline \multirow[t]{6}{*}{$\begin{array}{c}\mathrm{AB} \\
\text { (no covariates) }\end{array}$} & -6.56 & 2351 & -481620 & $\begin{array}{l}\text { Bilateral inferior and middle frontal } \\
\text { gyrus }\end{array}$ \\
\hline & -6.35 & 8110 & $-18-6856$ & $\begin{array}{l}\text { Precuneus, bilateral inferior and } \\
\text { superior parietal lobule }\end{array}$ \\
\hline & -5.44 & 1599 & 483812 & Superior and inferior frontal gyrus \\
\hline & -4.85 & 459 & 24040 & $\begin{array}{l}\text { Superior medial frontal cortex, } \\
\text { supplemental motor area }\end{array}$ \\
\hline & -4.75 & 234 & $-8-346$ & Extra nuclear, posterior cingulate \\
\hline & -3.98 & 347 & $-20-762$ & Middle occipital gyrus \\
\hline \multirow{8}{*}{$\begin{array}{c}\mathrm{AB} \\
\text { (with CU traits \& } \\
\text { demographic } \\
\text { covariates) }\end{array}$} & -6.80 & 2702 & $24-6452$ & Superior and inferior parietal lobule \\
\hline & -6.34 & 1223 & 484014 & Inferior and middle frontal gyrus \\
\hline & -6.04 & 1158 & -481620 & Inferior and middle frontal gyrus \\
\hline & -5.55 & 1851 & $-16-6856$ & Superior and inferior parietal lobule \\
\hline & -5.26 & 950 & $22-848$ & Middle frontal gyrus \\
\hline & -5.12 & 1101 & $-12-3228$ & Extra nuclear, posterior cingulate \\
\hline & -4.92 & 497 & 24240 & $\begin{array}{l}\text { Superior medial frontal cortex, dorsal } \\
\text { anterior cingulate, supplemental motor } \\
\text { area }\end{array}$ \\
\hline & -4.19 & 151 & $-30-444$ & Precentral gyrus \\
\hline \multirow[t]{3}{*}{$\begin{array}{l}\text { AB x CU Traits } \\
\text { (no covariates) }\end{array}$} & -7.04 & 4931 & -501028 & $\begin{array}{l}\text { Inferior and middle frontal gyrus, } \\
\text { inferior and superior parietal lobule }\end{array}$ \\
\hline & -6.66 & 8923 & $10-7254$ & $\begin{array}{l}\text { Inferior parietal lobule, superior parietal } \\
\text { lobule, angular gyrus, anterior cingulate, } \\
\text { middle frontal gyrus }\end{array}$ \\
\hline & -5.44 & 159 & $56-62-2$ & Middle temporal gyrus \\
\hline
\end{tabular}

Note. Associations between $A B$ and $C U$ traits factors and neural response to reward and loss. Additional analyses were conducted to thoroughly assess neural response to reward and loss in $A B$ and $C U$ traits. Analyses tested zero-order associations (i.e., $A B$ without covariates, $C U$ traits without covariates, $A B \times C U$ traits interaction without covariates) and when accounting for the overlap between $A B$ and $C U$ traits (i.e., $\mathrm{AB}$ controlling for $\mathrm{CU}$ traits and demographic covariates and vice versa). Results were largely similar to those reported in the main text, however associations between CU traits and Loss Outcome>No Loss were not significant without including demographic covariates or when controlling for overlap with $A B$. 


\section{References}

Casey, B., Cannonier, T., Conley, M. I., Cohen, A. O., Barch, D. M., Heitzeg, M. M., . . Garavan, H. (2018). The adolescent brain cognitive development $(A B C D)$ study: imaging acquisition across 21 sites. Developmental cognitive neuroscience, 32, 43-54.

Knutson, B., Fong, G. W., Adams, C. M., Varner, J. L., \& Hommer, D. (2001). Dissociation of reward anticipation and outcome with event-related fMRI. Neuroreport, 12(17), 3683-3687.

Murray, L., Lopez-Duran, N. L., Mitchell, C., Monk, C. S., \& Hyde, L. W. (2020). Neural mechanisms of reward and loss processing in a low-income sample of at-risk adolescents. Social cognitive and affective neuroscience, 15(12), 1310-1325. doi:10.1093/scan/nsaa157 \%J Social Cognitive and Affective Neuroscience.

Muthén, L. K., \& Muthén, B. O. (2014). Mplus 7.3. Los Angeles, CA: Muthén \& Muthén.

Waller, R., Wright, A. G., Shaw, D. S., Gardner, F., Dishion, T. J., Wilson, M. N., \& Hyde, L. W. (2015). Factor structure and construct validity of the parent-reported Inventory of Callous-Unemotional Traits among high-risk 9-year-olds. Assessment, 22(5), 561-580. 